\title{
Talent Crisis and Coping Strategies of Middle and Low Star-rated Tourist Hotels in Dujiangyan City
}

\author{
Ying Dong ${ }^{1}$, Denghuo Cai ${ }^{1}$ \\ ${ }^{1}$ Sichuan Technology and Business College, Dujiangyan, 611830, China
}

Keywords: Human resources. Dujiangyan. Middle and low star-rated tourist hotels. Talent crisis. Coping strategies

\begin{abstract}
In today's era of mass tourism, accommodation consumption cannot be underestimated. As subjects of mass tourism accommodation market, middle and low star-rated tourist hotels shall not be ignored. Dujiangyan, an international tourism city, shall attach importance to competitiveness and attractiveness of local middle and low star-rated tourist hotels. At present, talent crisis has become a bottleneck of the development of middle and low star-rated tourist hotels in Dujiangyan City. This paper centers and highlights on causes of this crisis and effective coping strategies.
\end{abstract}

\section{Definition of middle and low star-rated tourist hotels}

Middle and low star-rated tourist hotels refer to those named according to National Star-rating Standards for Tourist Hotels, including one-star, two-star and three-star hotels and excluding any budget hotels.

\section{Current situation of talent crisis of middle and low star-rated tourist hotels in Dujiangyan City}

\section{Lack of professionals}

Professionals mainly refer to the following two categories of talents: firstly, management professionals, which refer to business managers who are well-educated, proficient in management and innovative; secondly, chefs with professional skills. According to investigation of professionals of middle and low star-rated tourist hotels in Dujiangyan City, these hotels have a lack of professionals, and thus can hardly form core competitiveness and establish strong brands, let alone attracting customers.

\section{Imbalanced talent structure}

According to investigation of educational degree of practitioners of middle and low star-rated tourist hotels in Dujiangyan City, about 49\% of them have a degree of junior high school or below; about $42 \%$ of practitioners have a degree of technical secondary school (including high school and vocational high school); $7 \%$ of them have a degree of junior college (including degree obtained through further education); and $2 \%$ of them have a bachelor's degree or above.

According to investigation of major structure of managers of middle and low star-rated tourist hotels in Dujiangyan City, about 2\% of them have once majored in tourism management; about 6\% of them have once majored in other categories of management; and 92\% of them have once majored in other non-management categories.

According to investigation of age structure of practitioners of middle and low star-rated tourist hotels in Dujiangyan City, about 25\% of them are 25 years old or below; about $41 \%$ of them are between 26 and 35 years old; about 21\% of them are between 36 and 45 years old; about $10 \%$ of them are between 46 and 55 years old; and about $3 \%$ of them are 56 years old or above.

Hotels are traditional labor-intensive industry with centralized manpower. However, according to the above investigation of educational degree, major structure and age structure, manpower structure of these hotels is in a critical situation. Facing challenges in the new era, it is necessary to re-examine such basic framework at present. In particular, from the perspective of sustainable development, it is in urgent need to improve human resources structure of the entire hotel industry.

\section{Serious talent drain}


According to investigation of duration of employees of middle and low star-rated tourist hotels in Dujiangyan City, 24\% of them have duration of no more than 1 year (inclusive); $45 \%$ of them have duration of 1-5 years (inclusive); 23\% of them have duration of 5-10 years (inclusive); and 8\% of them have duration of above 10 years. According to investigation of employee turnover rate of middle and low star-rated tourist hotels in Dujiangyan City, employee turnover rates are 18\%, 21\% and $33 \%$ in recent three years respectively, with an average turnover rate of $24 \%$. The above data indicates unstable employee status and serious talent drain. Moderate employee turnover can optimize hotel employee structure, and bring vitality and vigor to hotels. However, too high turnover rate would bring a series of problems, such as unstable services and food quality, and high management cost etc.

\section{Analysis of causes of talent crisis of middle and low star-rated tourist hotels in Dujiangyan City}

\section{Social causes}

\section{Sharply increasing number of hotels, resulting in increased lack of talents}

After 5.12 Wenchuan Earthquake, hotels and catering enterprises develop rapidly in Dujiangyan. As of the end of 2012, Dujiangyan City had more than 1,300 hotels and catering enterprises, including 1 five-star hotel, 1 four-star hotel, 10 three-star hotels, 1 two-star hotel, and other budget hotels, social hotels, rural hotels and happy farmhouses. Such rapid development leads to sharply increasing talent demands of hotels and increased lack of talents. Naturally, middle and low star-rated tourist hotels are no exception.

\section{Existence of social prejudice}

It is traditionally believed in China that only "official career" is man's world, and brings glory on their ancestors. It is generally believed that hotel jobs need "young" employees, have instability, and "hotel jobs" require employees to serve others. Due to influence of these traditional concepts, many employees worry about later life, and believe that service work is inferior to others with no future. Most hotel staffs come to work in hotels when they have nowhere to go, take hotel jobs as temporary and staged occupations, and would leave and work in other industries if there are any opportunities.

\section{Enterprise causes}

\section{Low salary}

By analyzing reasons for leaving of former employees, salary is the most important influencing factor that employees leave. According to investigation of middle and low star-rated hotels in Dujiangyan City, annual average salary of employees was RMB 19,878.00 in 2012, with a monthly average of RMB 1,656.5; and it was even lower for some temporary employees, trainees and interns. With such low salary, some employees may job-hop if there is an enterprise which provides higher salary.

\section{High labor intensity}

Some hotels have not scientific job responsibilities for positions, irrational job responsibility allocation and unclear job boundaries, and thus increase labor intensity of employees artificially. Some hotels even require employees to work for up to 72 hours per week, including 36 hours of night shift, and thus their work is obviously laborious. Key technical managers of some hotels often require employees to keep their mobile phones on for 24 hours a day and be available on hand. In this way, even if there is certain economic compensation, employees may leave due to such labor intensity as time goes on.

\section{Training cannot be followed up}

According to investigation of middle and low star-rated tourist hotels in Dujiangyan City, training expenditure per employee accounts for $0.8 \%$ of operating revenue in recent three years; and 96 employees have been sent to receive training in recent three years, accounting for $4.5 \%$ of the total number of employees.

As we all know, hotels belong to service industry, and employees' qualities affect directly service quality of hotels. Middle and low star-rated hotels provide limited services, and the hardware facilities cannot compare favorably with high-star hotels which provide full services. If no training is 
provided to improve employees' qualities and follow up service quality, hotels will have plummeting attractiveness to customers, and thus affect their economic benefits directly.

\section{Personal causes}

\section{The gap between too high expectation and reality leads to talent drain}

The gap between too high expectation and reality is also a major factor that leads to talent drain. Some employees and especially those who graduate from junior colleges and technical secondary schools find that hotel jobs are not as good as imagined when they work in middle and low star-rated hotels due to long working hours and high labor intensity, and would leave.

\section{Other personal causes}

Some employees may also decide to leave out of personal causes besides work. For example, some young employees would give up current jobs to continue to learn.

\section{Coping strategies of talent crisis of middle and low star-rated tourist hotels in Dujiangyan City}

\section{Increase salary}

"Low salary" is a major and the most direct cause of talent drain, as salary not only improves their life and reflects their values; but also meets their fundamental physiological needs and high needs of respect and self-realization etc. It is of very important significance to keep salary competitive, so as to retain talents.

\section{Lay emphasis on spiritual motivation}

Spiritual motivation, also known as intrinsic motivation or intangible motivation, is to authorize employees, accept employees' work, establish an open and fair promotion system, provide opportunities for employees to learn and improve themselves, implement flexible job system and develop career development paths that suit for characteristics of each employee etc. Spiritual motivation is an effective way to stimulate employees' enthusiasm, initiative and creativity. Middle and low star-rated hotel managers shall do well in spiritual motivation, regard employees as "relatives"; respect employees' personal dignity; create relaxing and pleasant work atmosphere; make employees fully have fun in work; listen modestly to and adopt timely employees' rational recommendations; and tolerate employees' mistakes etc.

\section{Relieve labor intensity appropriately}

Hotel is a special industry with different working hours from other industries, and it is usually busy when other industries are of leisure time. Such specificity reminds that hotel managers shall attach importance to the work and vacation system of hotel employees. Good and rational work division and arrangement can help improve employees' service quality and enhance hotels' service level. So, hotel managers shall analyze work seriously, design job responsibilities scientifically, define job responsibilities, rights and benefits rationally, optimize service procedures, and do not increase labor intensity artificially. Meanwhile, hotels shall increase time for employees to rest and relax.

\section{Attach importance to building of corporate culture}

Stable development of middle and low star-rated tourist hotels relies on facilities and soft strengths, and the latter is mainly reflected in building corporate culture. For a very long time, some Chinese hotels and catering enterprises have misunderstandings in terms of cultural construction, and believe that cultural construction means blackboard newspaper, slogans and recreational activities, and some consider that cultural construction means spiritual civilization. Cause of these misunderstandings is the lack of understanding of connotation of building corporate culture in terms of both depth and breadth. Middle and low star-rated tourist hotels shall always take people orientation, sincere services and honest dedication as the core of building corporate culture, extract appropriate core values and business philosophy, create corporate soul of all for employees, customers, quality, honor and learning, and strengthen ideological and political construction constantly, so that enterprises could always make achievements in both economic and social benefits.

China has currently entered the era of mass tourism with a huge cardinal amount of accommodation consumption, and thus middle and low star-rated hotels shall not be underestimated 
as subjects of mass tourism accommodation market. As an international tourism city, Dujiangyan City shall not ignore competitiveness and attractiveness of middle and low star-rated tourist hotels. However, talent crisis has currently become a bottleneck of the development of middle and low star-rated tourist hotel in Dujiangyan City, and a big setback and difficulties may be encountered if crisis is not changed into opportunities timely. Therefore, the talent construction has a long way to go.

\section{References}

[1] Pan Zhibo, Wang Ziyuan. Study on the Application of Human Resources Management "Incentive System” in China’s Hotel Industry [J]. Enterprise Economy, 2004 (12).

[2] Zhao Shide, Hu Shanfeng, Deng Hongwei. Analysis of Causes and Countermeasures of Tourist Hotel Talent Drain [J]. Journal of Huainan Teachers College, 2006 (03).

[3] Li Shuifeng. Causes and Countermeasures of Talent Drain in China's Tourist Hotels. Journal of Yunnan University of Finance and Economics, 2003, 8.

[4] Yan Kuanrong. Current Situation and Coping Measures of Talent Crisis of Tourist Hotel Industry. Journal of Tianjin Manager College, 2010 (01). 